\title{
Sensorless Control of Permanent Magnet Synchronous Motors with Compensation for Parameter Uncertainty
}

\author{
Jiaqiang Yang*, Yongle Mao ${ }^{\dagger}$ and Yangsheng Chen*
}

\begin{abstract}
Estimation errors of the rotor speed and position in sensorless control systems of Permanent Magnet Synchronous Motors (PMSM) will lead to low efficiency and dynamic-performance degradation. In this paper, a parallel-type extended nonlinear observer incorporating the nominal parameters is constructed in the stator-fixed reference frame, with rotor position, speed, and the load torque simultaneously estimated. The stability of the extended nonlinear observer is analyzed using the indirect Lyapunov's method, and observer gains are selected according to the transfer functions of the speed and position estimators. Taking into account the parameter inaccuracies issue, explicit estimation error equations are derived based on the error dynamics of the closed-loop sensorless control system. An equivalent flux error is defined to represent the back Electromotive Force (EMF) error caused by the inaccurate motor parameters, and a compensation strategy is designed to suppress the estimation errors. The effectiveness of the proposed method has been validated through simulation and experimental results.
\end{abstract}

Keywords: Extended nonlinear observer, Parameter uncertainty compensation, Permanent magnet synchronous motor, Sensorless control

\section{Introduction}

Permanent Magnet Synchronous Motor (PMSM) is superior for its high power density, high dynamic response, and high efficiency over wide speed range, and is extensively used in vehicle propulsions, wind power systems, and industrial applications [1-3]. The rotor position information is indispensable for speed feed-back control and coordinate transformation in high performance field oriented control systems for PMSM, which is usually obtained through a mechanical position sensor. Since the mechanical position sensors, such as resolvers and encoders, are vulnerable to strong vibration, high operating temperature and humid atmosphere, sensorless control of PMSM has been the research focus by extracting the position information from terminal voltages and currents, which can be separated into saliency- and model-based sensorless methods $[4,5]$. The saliency-based highfrequency signal injection methods, which exploits rotor position dependent inductance properties, are appropriate only for low and zero speeds due to the constraints of constant DC voltage and high-frequency noise [6-8].

The model-based sensorless methods are widely used in medium to high speed range for their simplicity and high efficiency, which mainly include back-EMF (electro motive force) estimation based method, sliding-mode observer (SMO), extended Kalman filter (EKF), model

\footnotetext{
$\dagger$ Corresponding Author: College of Electrical Engineering, Zhejiang

University, China. (maoyongle@zju.edu.cn)

* College of Electrical Engineering, Zhejiang University, China.

(yjq1998@163.com, yschen@zju.edu.cn)

Received: June 20, 2016; Accepted: February 6, 2017
}

reference adaptive system (MRAS), and nonlinear observer, etc. Linear state observers are constructed in the estimated synchronous reference frame to estimate the back-EMF by assuming it to be constant in a very short time, and rotor speed and position are sequentially extracted with arctangent or phase-locked loop (PLL) [9, 10]. The SMO is employed to estimate the speed and position in the statorfixed reference frame [11-14]. Although the two-order SMO is very attractive for its simplicity and robustness against system noise, modifications are required to mitigate the chattering of SMO, such as replacing signum function with sigmoid/saturation function or constructing highorder SMO. The EKF, which is an optimal estimator in the least-square sense, is implemented for speed and position estimation with high reliability $[15,16]$. However, the EKF requires complex matrices computation and proper initialization for covariance matrix. Compared with the EKF, the MRAS is much simpler, and is successfully extended to PMSM for sensorless control, along with motor parameters simultaneously identified based on EKF or additional MRAS estimator [17, 18]. As the rotor position is estimated from the integration of the estimated speed without any adjustment scheme, errors might propagate in the sequentially connected estimation loops. The nonlinear observer proposed by $[19,20]$ is capable of estimating the speed and position of PMSM simultaneously, and is a good candidate for high dynamic sensorless control. Genetic algorithms, employing the principles of evolution, natural selection, and genetic mutation, are introduced for the selection of nonlinear observer gains [21]. To improve the observer performance against load 
variations, an extended nonlinear observer is proposed to estimate the stator current, rotor position and speed, as well as the load torque simultaneously [22]. However, the nonlinear observer shows sensitivity to electrical parameter variations, and estimation errors of the speed and position may arise if the motor parameters adopted in the observer are inaccurate, leading to poor dynamic performance and low efficiency.

In this paper, the effects of inaccurate motor parameters on the estimation of rotor speed and position are investigated, and instead of precisely identifying each motor parameter, an equivalent flux error is defined and compensated to suppress the estimation errors of the extended nonlinear observer. The rest of this paper is organized as follows. In Section 2, a full-order extended nonlinear observer is built in the stator-fixed coordinate frame, with rotor position, speed, and load torque simultaneously estimated. In Section 3, explicit estimation error equations are derived; and an equivalent flux error representing the effects of inaccurate parameters is defined and compensated to suppress the estimation errors. Experimental setup and evaluation of the proposed method are provided in Section 4.

\section{Sensorless Control Based on the Extended Nonlinear Observer}

In this section, a full-order extended nonlinear observer is built in the stator-fixed coordinate frame incorporating the electrical and mechanical equations of PMSM.

\subsection{Extended nonlinear observer for PMSM}

The electrical and mechanical equations of PMSM in the $\alpha-\beta$ frame are directly given as:

$$
\begin{gathered}
\left(\begin{array}{c}
u_{\alpha} \\
u_{\beta}
\end{array}\right)=-R_{\mathrm{s}}\left(\begin{array}{c}
i_{\alpha} \\
i_{\beta}
\end{array}\right)+L_{\mathrm{s}} \frac{d}{d t}\left(\begin{array}{c}
i_{\alpha} \\
i_{\beta}
\end{array}\right)+P_{\mathrm{n}} \omega_{\mathrm{m}} \psi_{\mathrm{f}}\left(\begin{array}{c}
-\sin \theta_{\mathrm{e}} \\
\cos \theta_{\mathrm{e}}
\end{array}\right) \\
\left(\begin{array}{c}
\dot{\omega}_{\mathrm{m}} \\
\dot{\theta}_{\mathrm{e}}
\end{array}\right)=\left(\begin{array}{ll}
0 & 0 \\
1 & 0
\end{array}\right)\left(\begin{array}{c}
\omega_{\mathrm{m}} \\
\theta_{\mathrm{e}}
\end{array}\right)+\frac{1}{J}\left(\begin{array}{c}
T_{\mathrm{e}}-B \omega_{\mathrm{m}}+T_{\mathrm{L}} \\
0
\end{array}\right)
\end{gathered}
$$

where, $u_{\alpha}$ and $u_{\beta}$ are the stator voltages in the $\alpha-\beta$ frame;.$i_{\alpha}$ and $i_{\beta}$ are the stator currents in the $\alpha-\beta$ frame; $L_{\mathrm{s}}, R_{\mathrm{s}}$ are the stator resistance and inductance respectively; $\psi_{\mathrm{f}}$ is the Permanent Magnet (PM) fluxlinkage; $\omega_{\mathrm{m}}$ and $\theta_{\mathrm{e}}$ are the mechanical speed and electrical position respectively; $P_{\mathrm{n}}$ is the motor pole pairs; $J$ and $B$ are the system inertia and friction coefficient respectively; $T_{e}, T_{L}$ are the electromagnetic torque and load torque respectively, and $T_{e}=1.5 P_{n} \psi_{f}\left(-i_{\alpha} \sin \theta_{e}+i_{\beta} \cos \theta_{e}\right)$.

The full-order dynamic model of PMSM can be readily established based on (1) and (2), with state variables to be $i_{\alpha}, i_{\beta}, \omega_{\mathrm{m}}$, and $\theta_{\mathrm{e}}$, which is express as:

$$
\left(\begin{array}{c}
\dot{i}_{\alpha} \\
\dot{i}_{\beta} \\
\dot{\omega}_{\mathrm{m}} \\
\dot{\theta}_{\mathrm{e}}
\end{array}\right)=\left(\begin{array}{c}
\left(-R_{\mathrm{s}} i_{\alpha}+P_{\mathrm{n}} \omega_{\mathrm{m}} \psi_{\mathrm{f}} \sin \theta_{\mathrm{e}}+u_{\alpha}\right) / L_{\mathrm{s}} \\
\left(-R_{\mathrm{s}} i_{\beta}-P_{\mathrm{n}} \omega_{\mathrm{m}} \psi_{\mathrm{f}} \cos \theta_{\mathrm{e}}+u_{\beta}\right) / L_{\mathrm{s}} \\
\left(T_{e}-B \omega_{\mathrm{m}}-T_{\mathrm{L}}\right) / J \\
P_{\mathrm{n}} \omega_{\mathrm{m}}
\end{array}\right)
$$

Note that, compared with the system sampling frequency (typically the PWM frequency), the load torque, which is generally unknown in practical systems, can be safely assumed to be constant during a very short time. In order to extract the speed and position from the information of stator voltages and currents instead of installing a mechanical position sensor, a full-order extended nonlinear observer with load torque estimation is built in the $\alpha-\beta$ frame based on the dynamic model of PMSM, as shown in (4). Estimation errors of the stator currents $\left(\Delta i_{\alpha}, \Delta i_{\beta}\right)$ are used to regulate the estimated speed, position, and load torque.

$$
\left(\begin{array}{c}
\dot{\hat{i}}_{\alpha} \\
\dot{\hat{i}}_{\beta} \\
\dot{\hat{\omega}}_{\mathrm{m}} \\
\dot{\hat{\theta}}_{\mathrm{e}} \\
\dot{\hat{T}}_{\mathrm{L}}
\end{array}\right)=\left(\begin{array}{c}
\left(-\hat{R}_{\mathrm{s}} \hat{i}_{\alpha}+P_{\mathrm{n}} \hat{\omega}_{\mathrm{m}} \hat{\psi}_{\mathrm{f}} \sin \hat{\theta}_{\mathrm{e}}+u_{\alpha}\right) / \hat{L}_{\mathrm{s}} \\
\left(-\hat{R}_{\mathrm{s}} \hat{i}_{\beta}-P_{\mathrm{n}} \hat{\omega}_{\mathrm{m}} \hat{\psi}_{\mathrm{f}} \cos \hat{\theta}_{\mathrm{e}}+u_{\beta}\right) / \hat{L}_{\mathrm{s}} \\
\left(T_{\mathrm{e}}^{\prime}-B \hat{\omega}_{\mathrm{m}}-\hat{T}_{\mathrm{L}}\right) / J \\
P_{\mathrm{n}} \hat{\omega}_{\mathrm{m}} \\
0
\end{array}\right)+\mathrm{K}\left(\begin{array}{c}
\hat{L}_{\mathrm{s}} \Delta i_{\alpha} \\
\hat{L}_{\mathrm{s}} \Delta i_{\beta}
\end{array}\right)
$$

where, variables with ' $\wedge$ ' denote the estimated values, while parameters with ' $\wedge$ ' stand for the nominal values of the motor parameters adopted in the extended nonlinear observer; $\boldsymbol{K}$ is the nonlinear observer gain matrix; $T_{\mathrm{e}}^{\prime}$ is the electromagnetic torque calculated in the $\alpha-\beta$ frame based on the estimated rotor position, which can be expressed as:

$$
T_{\mathrm{e}}^{\prime}=1.5 P_{\mathrm{n}} \hat{\psi}_{\mathrm{f}}\left(-i_{\alpha} \sin \hat{\theta}_{\mathrm{e}}+i_{\beta} \cos \hat{\theta}_{\mathrm{e}}\right)
$$

For asymptotic convergence of the extended nonlinear observer, the state-linearization method is utilized to determine the structure of the observer gain matrix. By transforming the PMSM model and the extended nonlinear observer to the polar coordinate frame with the nonlinear coordinate transformation given in (5), linearized observer gain matrix can be determined employing the linear control theory. To avoid ambiguity in the sign of the estimated speed, a reverse transformation to the $\alpha-\beta$ frame is implemented with (6). More details on the observer gain matrix derivation can be found in [20-22] and the references therein.

$$
\mathrm{z}=\left(\begin{array}{c}
z_{1} \\
z_{2}
\end{array}\right)=\Phi\left(\omega_{\mathrm{m}}, \theta_{\mathrm{e}}\right)=\left(\begin{array}{c}
P_{\mathrm{n}} \omega_{\mathrm{m}} \psi_{\mathrm{f}} \sin \theta_{\mathrm{e}} \\
-P_{\mathrm{n}} \omega_{\mathrm{m}} \psi_{\mathrm{f}} \cos \theta_{\mathrm{e}}
\end{array}\right)
$$




$$
\begin{aligned}
\left(\begin{array}{c}
\dot{\omega}_{\mathrm{m}} \\
\dot{\theta}_{\mathrm{e}}
\end{array}\right) & =\left(\frac{\partial \Phi\left(\omega_{\mathrm{m}}, \theta_{\mathrm{e}}\right)}{\partial\left(\omega_{\mathrm{m}} \theta_{\mathrm{e}}\right)^{\mathrm{T}}}\right)^{-1} \dot{\mathrm{z}} \\
& =\left(\begin{array}{cc}
P_{\mathrm{n}} \psi_{\mathrm{f}} \sin \theta_{\mathrm{e}} & P_{\mathrm{n}} \omega_{\mathrm{m}} \psi_{\mathrm{f}} \cos \theta_{\mathrm{e}} \\
-P_{\mathrm{n}} \psi_{\mathrm{f}} \cos \theta_{\mathrm{e}} & P_{\mathrm{n}} \omega_{\mathrm{m}} \psi_{\mathrm{f}} \sin \theta_{\mathrm{e}}
\end{array}\right)\left(\begin{array}{l}
\dot{z}_{1} \\
\dot{z}_{2}
\end{array}\right)
\end{aligned}
$$

The ultimate expression of the observer gain matrix in the $\alpha-\beta$ frame is obtained as:

$$
\boldsymbol{K}=\left(\begin{array}{lll}
K_{\alpha \beta} \boldsymbol{I} & K_{\mathrm{z}} \boldsymbol{\Lambda} & K_{\mathrm{d}} \boldsymbol{\Gamma}
\end{array}\right)^{\mathrm{T}}
$$

where, $K_{\alpha \beta}, K_{\mathrm{z}}$, and $K_{\mathrm{d}}$ are constant and positive observer gains, and:

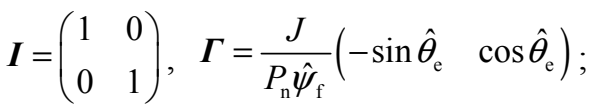

$$
\begin{aligned}
& \boldsymbol{\Lambda}=\frac{1}{P_{\mathrm{n}} \hat{\omega}_{\mathrm{m}} \hat{\psi}_{\mathrm{f}}}\left(\begin{array}{cc}
\hat{\omega}_{\mathrm{m}} \sin \hat{\theta}_{\mathrm{e}} & -\hat{\omega}_{\mathrm{m}} \cos \hat{\theta}_{\mathrm{e}} \\
\cos \hat{\theta}_{\mathrm{e}} & \sin \hat{\theta}_{\mathrm{e}}
\end{array}\right) .
\end{aligned}
$$

\subsection{Observer gain selection}

The schematic diagram of the rotor speed and position estimators can be drawn based on the extended nonlinear observer (4), as shown in Fig. 1. It is clear that the structure of the extended nonlinear observer belongs to the parallel-type, with the estimated rotor speed and position simultaneously adjusted by the stator current estimation errors. Note that the structure of the extended nonlinear observer is different from the cascade type, in which only the estimated rotor speed is directly adjusted by system states, with the estimated position obtained from the integration of the estimated speed, and vice versa.

To investigate the dynamic performance of the extended nonlinear observer, the transfer function from the backEMF estimation error to the current estimation error can be obtained by subtracting (4) from (3) and transforming to the s-domain, under the assumption that accurate motor parameters are adopted.

$$
\left\{\begin{array}{l}
\Delta i_{\alpha}=\frac{1}{s+K_{\alpha \beta}^{\prime}} \frac{P_{\mathrm{n}} \psi_{\mathrm{f}}\left(\omega_{\mathrm{m}} \sin \theta_{\mathrm{e}}-\hat{\omega}_{\mathrm{m}} \sin \hat{\theta}_{\mathrm{e}}\right)}{L_{\mathrm{s}}} \\
\Delta i_{\beta}=-\frac{1}{s+K_{\alpha \beta}^{\prime}} \frac{P_{\mathrm{n}} \psi_{\mathrm{f}}\left(\omega_{\mathrm{m}} \cos \theta_{\mathrm{e}}-\hat{\omega}_{\mathrm{m}} \cos \hat{\theta}_{\mathrm{e}}\right)}{L_{\mathrm{s}}}
\end{array}\right.
$$

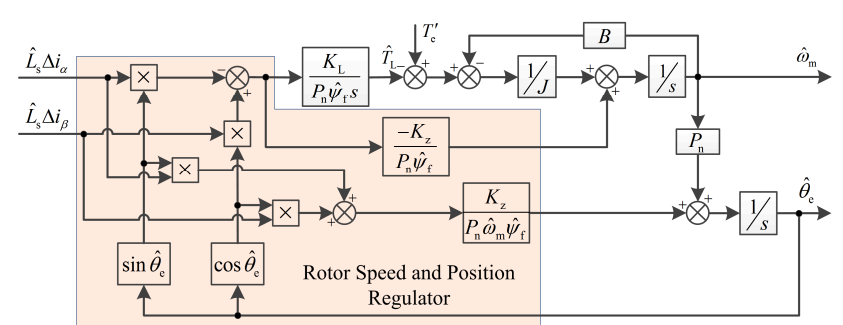

Fig. 1. Schematic structure of the parallel-type rotor speed and position estimators where $K_{\alpha \beta}^{\prime}=K_{\alpha \beta}+R_{\mathrm{s}} / L_{\mathrm{s}}$.

Estimation errors of rotor speed and position can be defined as:

$$
\Delta \omega_{\mathrm{m}}=\omega_{\mathrm{m}}-\hat{\omega}_{\mathrm{m}}, \Delta \theta_{\mathrm{e}}=\theta_{\mathrm{e}}-\hat{\theta}_{\mathrm{e}}
$$

Based on Fig. 1 and (8), the speed and position estimators can be represented by two closed-loop tracking control systems, as shown in Fig. 2.

According to Fig. 2, the estimated rotor speed and position in s-domain can be expressed as:

$$
\begin{aligned}
& \hat{\omega}_{\mathrm{m}}=\frac{\left(K_{\mathrm{z}} s+K_{\mathrm{L}}\right) \omega_{\mathrm{m}}}{s^{3}+K_{\alpha \beta}^{\prime} s^{2}+K_{\mathrm{z}} s+K_{\mathrm{L}}}+\frac{s\left(s+K_{\alpha \beta}^{\prime}\right) T_{\mathrm{e}}^{\prime} / J}{s^{3}+K_{\alpha \beta}^{\prime} s^{2}+K_{\mathrm{z}} s+K_{\mathrm{L}}} \\
& \hat{\theta}_{\mathrm{e}}=\frac{\left(\omega_{\mathrm{m}} / \hat{\omega}_{\mathrm{m}}\right) K_{z} \theta_{\mathrm{e}}}{s^{2}+K_{\alpha \beta}^{\prime} s+\left(\omega_{\mathrm{m}} / \hat{\omega}_{\mathrm{m}}\right) K_{z}}+\frac{\left(s+K_{\alpha \beta}^{\prime}\right) P_{\mathrm{n}} \hat{\omega}_{\mathrm{m}}}{s^{2}+K_{\alpha \beta}^{\prime} s+\left(\omega_{\mathrm{m}} / \hat{\omega}_{\mathrm{m}}\right) K_{z}}
\end{aligned}
$$

It can be seen from (10) and (11) that the poles and zeroes of the closed-loop transfer functions are nearly constant under different speed conditions (assuming $\left.\hat{\omega}_{\mathrm{m}} \approx \omega_{\mathrm{m}}\right)$. The observer gains can be selected to fulfill the expected tracking bandwidth and damping coefficient using the Root Locus or Bode Diagrams, under the stability constraint of $K_{\mathrm{L}}<K_{\alpha \beta}^{\prime} K_{\mathrm{z}}$ (see Appendix A).

\subsection{Sensorless control system for PMSM}

Fig. 3 shows the block diagram of the overall sensorless control system for PMSM based on the extended nonlinear observer, consisting of a speed proportional-integral (PI)

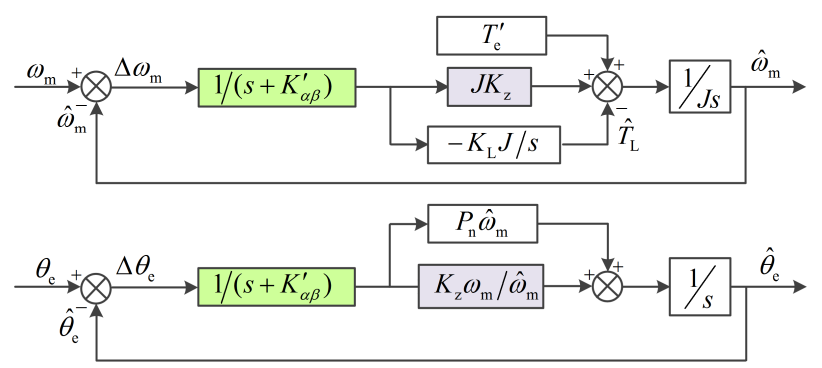

Fig. 2. Block diagram of the speed and position estimators

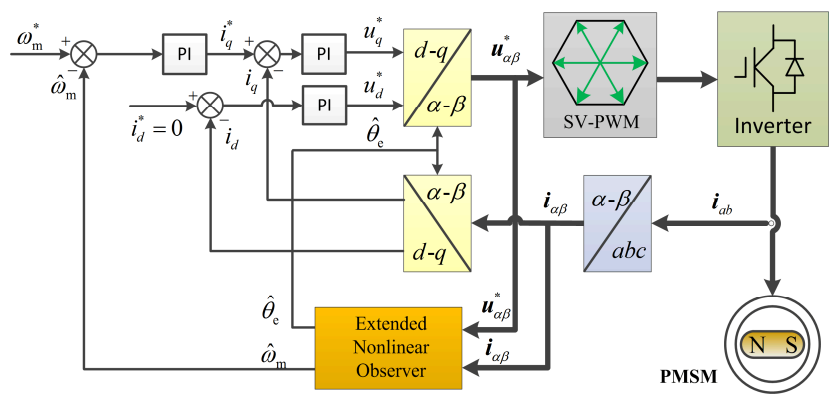

Fig. 3. Block diagram of the sensorless control system of PMSM 
regulator and two current PI regulators implemented in the synchronous rotating reference frame (SRRF).

As depicted in Fig. 3, the speed for feed-back control and the rotor position for coordinate transformation are obtained from the extended nonlinear observer, instead of a mechanical position sensor. $i_{d}^{*}=0$ control is used in the constant-torque mode, while the torque current reference $i_{q}^{*}$ is generated from the speed tracking error. The voltage references $\left(u_{d}^{*}, u_{q}^{*}\right)$ in the SRRF are obtained from current tracking errors of $d, q$ axes, and are transformed to the stator-fixed reference frame as $u_{\alpha \beta}^{*}$, which is the voltage reference for SV-PWM.

\section{Estimation Errors and Compensation Strategy}

In this section, explicit estimation errors of the rotor speed and position due to the parameter inaccuracies are calculated and analyzed, and a compensation strategy is designed to suppress the estimation errors.

\subsection{Estimation errors analysis}

It has been well studied that the motor parameters tend to vary with different operating conditions. For instance, the stator resistance and PM flux-linkage are functions of the stator and rotor temperatures respectively, while the stator inductance changes with the magnetic level. It should be noted that the stator resistance could increase to $150 \%$ of its nominal value, and the PM flux-linkage may decrease to $90 \%$ of its nominal value. Moreover, the effects of the stator resistance and the PM flux-linkage are dominant in causing position and speed estimation errors. Since the air-gap of the surface-mounted PMSM is relatively large, the stator inductance variation is small and can be safely ignored, i.e., $\hat{L}_{\mathrm{s}}=L_{\mathrm{s}}$. Errors between the actual motor parameters and their nominal values are defined as:

$$
\Delta R_{\mathrm{s}}=R_{\mathrm{s}}-\hat{R}_{\mathrm{s}}, \quad \Delta \psi_{\mathrm{f}}=\psi_{\mathrm{f}}-\hat{\psi}_{\mathrm{f}}
$$

The effects of the stator resistance and PM flux-linkage inaccuracies on the estimation of rotor speed and position are investigated through simulation, as shown in Fig. 4 and Fig. 5.

In Fig. 4, the stator resistance error varies from $-0.5 R_{\mathrm{s}}$ to $0.5 R_{\mathrm{s}}$ under the full-load condition, with the rotor speed ranges from $100 \mathrm{rpm}$ to $1500 \mathrm{rpm}$. From Fig. 4, it is clear that inaccurate stator resistance will cause large estimation errors of the speed and position, and they are both in proportion to the stator resistance error. In Fig. 5, the PM flux error varies from $0.9 \psi_{\mathrm{f}}$ to $1.1 \psi_{\mathrm{f}}$ under noload condition, with rotor speed ranges from $100 \mathrm{rpm}$ to $1500 \mathrm{rpm}$. It can be seen that the inaccurate PM fluxlinkage will also cause large estimation errors of the speed and position, and they are in proportion to both of the PM flux error and rotor speed.

By subtracting the extended nonlinear observer (4) from the dynamic model of PMSM (3), the estimation error dynamics of the sensorless control system is derived as:

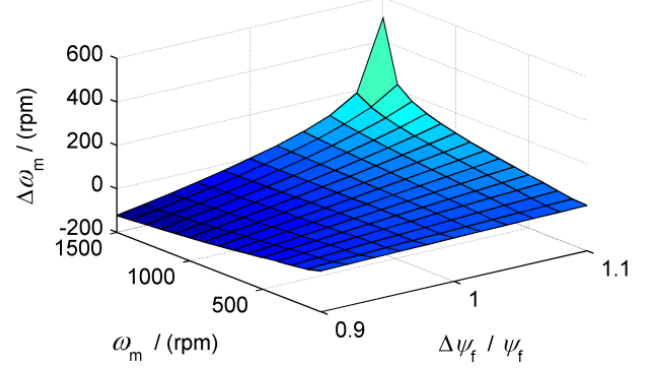

(a)

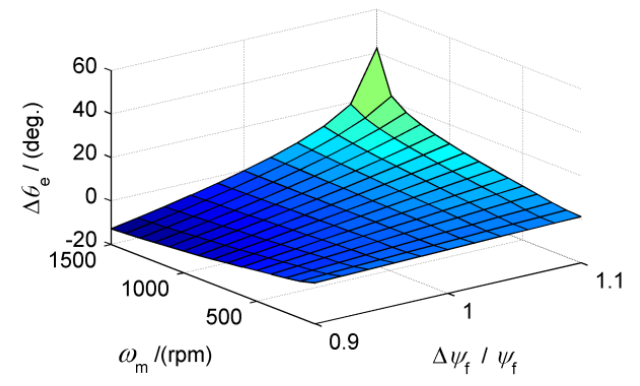

(b)

Fig. 5. Effects of the PM flux-linkage inaccuracy: (a) speed estimation error; (b) position estimation error
Fig. 4. Effects of the stator resistance inaccuracy: (a) speed estimation error; (b) position estimation error 
$\left(\begin{array}{c}L_{s} \Delta \dot{i}_{\alpha} \\ L_{s} \Delta \dot{i}_{\beta} \\ \Delta \dot{\omega}_{\mathrm{m}} \\ \Delta \dot{\theta}_{\mathrm{e}}\end{array}\right)=\left(\begin{array}{c}-\Delta R i_{\alpha}-\hat{R}_{\mathrm{s}} \Delta i_{\alpha}+\lambda_{\mathrm{r}}+\xi_{1} \\ -\Delta R i_{\beta}-\hat{R}_{\mathrm{s}} \Delta i_{\beta}+\lambda_{2}+\xi_{2} \\ \left(T_{e}-T_{e}^{\prime}-T_{\mathrm{L}}+\hat{T}_{\mathrm{L}}\right) / J-B \Delta \omega_{\mathrm{m}} / J \\ P_{\mathrm{n}} \Delta \omega_{\mathrm{m}}\end{array}\right)-\boldsymbol{K}_{\alpha \beta}\left(\begin{array}{c}L_{s} \Delta i_{\alpha} \\ L_{s} \Delta i_{\beta}\end{array}\right)$

where

$$
\begin{aligned}
& \left\{\begin{array}{l}
\lambda_{1}=P_{\mathrm{n}}\left(\hat{\omega}_{\mathrm{m}} \Delta \psi_{\mathrm{f}}+\Delta \omega_{\mathrm{m}} \psi_{\mathrm{f}}\right) \sin \hat{\theta}_{\mathrm{e}}+P_{\mathrm{n}} \omega_{\mathrm{m}} \psi_{\mathrm{f}} \sin \Delta \theta_{\mathrm{e}} \cos \hat{\theta}_{\mathrm{e}} \\
\lambda_{2}=P_{\mathrm{n}}\left(\hat{\omega}_{\mathrm{m}} \Delta \psi_{\mathrm{f}}+\Delta \omega_{\mathrm{m}} \psi_{\mathrm{f}}\right) \cos \hat{\theta}_{\mathrm{e}}+P_{\mathrm{n}} \omega_{\mathrm{m}} \psi_{\mathrm{f}} \sin \Delta \theta_{\mathrm{e}} \sin \hat{\theta}_{\mathrm{e}}
\end{array} ;\right. \\
& \left\{\begin{array}{l}
\xi_{1}=P_{\mathrm{n}} \omega_{\mathrm{m}} \psi_{\mathrm{f}} \sin \hat{\theta}_{\mathrm{e}}\left(\cos \Delta \theta_{\mathrm{e}}-1\right) \\
\xi_{2}=-P_{\mathrm{n}} \omega_{\mathrm{m}} \psi_{\mathrm{f}} \cos \hat{\theta}_{\mathrm{e}}\left(\cos \Delta \theta_{\mathrm{e}}-1\right)
\end{array}\right.
\end{aligned}
$$

To evaluate the effects of inaccurate parameters, the following approximations are made when the extended nonlinear observer converges to the equilibrium point.

1) The differences between the actual motor parameters and their nominal values are small, and the resultant rotor position estimation error is small, which yields $\sin \Delta \theta_{\mathrm{e}} \approx \Delta \theta_{\mathrm{e}}, \quad \cos \Delta \theta_{\mathrm{e}} \approx 1$.

2) The derivative of the estimated position is equal to the actual rotor speed, which indicates $d \hat{\theta}_{\mathrm{e}} / d t=P_{\mathrm{n}} \omega_{\mathrm{m}}$.

Based on the assumptions above, explicit estimation errors of rotor speed and position can be derived from the estimation error dynamics (13), as:

$$
\begin{gathered}
\Delta \omega_{\mathrm{m}}=-\frac{\Delta R_{\mathrm{s}} i_{q}+P_{\mathrm{n}} \omega_{\mathrm{m}} \Delta \psi_{\mathrm{f}}}{P_{\mathrm{n}} \hat{\psi}_{\mathrm{f}}} \\
\Delta \theta_{\mathrm{e}}=\frac{\Delta R_{\mathrm{s}} i_{d}}{P_{\mathrm{n}} \omega_{\mathrm{m}} \psi_{\mathrm{f}}}-\frac{K_{\alpha \beta}^{\prime} \hat{\omega}_{\mathrm{m}} \hat{\psi}_{\mathrm{f}}}{K_{\mathrm{z}} \omega_{\mathrm{m}} \psi_{\mathrm{f}}} \Delta \omega_{\mathrm{m}}
\end{gathered}
$$

where, $i_{d}$ and $i_{q}$ are the stator currents in the SRRF.

It can be inferred from (14) that the speed estimation error is merely caused by the back-EMF error of the $q$-axis, relating to $\Delta R_{\mathrm{s}}$ and $\Delta \psi_{\mathrm{f}}$. It can be seen from (15) that the rotor position estimation error consists of two components: the first is caused by the back-EMF error of the $d$-axis; the second is caused by speed estimation error, and is affected by the observer gains. Since $i_{d}=0$ control is commonly employed in the constant torque region, the first component of (15) is zero. Thus, the rotor position estimation error can be simplified to:

$$
\begin{aligned}
\Delta \theta_{\mathrm{e}} & =-\frac{K_{\alpha \beta}^{\prime} \hat{\omega}_{\mathrm{m}} \hat{\psi}_{\mathrm{f}}}{K_{\mathrm{z}} \omega_{\mathrm{m}} \psi_{\mathrm{f}}} \Delta \omega_{\mathrm{m}} \\
& =-\frac{K_{\alpha \beta}^{\prime} \hat{\omega}_{\mathrm{m}}}{K_{\mathrm{z}} \omega_{\mathrm{m}} \psi_{\mathrm{f}}}\left(\Delta R_{\mathrm{s}} i_{q}+P_{\mathrm{n}} \omega_{\mathrm{m}} \Delta \psi_{\mathrm{f}}\right)
\end{aligned}
$$

\subsection{Compensation for parameter uncertainties}

As is analyzed in the previous section, the estimation errors of rotor speed and position are essentially caused by the back-EMF estimation errors. Therefore, an equivalent flux error $\psi_{\text {equ }}$ is defined to represent the effects of the back-EMF error, which is expressed as:

$$
\psi_{\text {equ }}=\frac{\Delta R_{\mathrm{s}} i_{q}+P_{\mathrm{n}} \omega_{\mathrm{m}} \Delta \psi_{\mathrm{f}}}{P_{\mathrm{n}} \omega_{\mathrm{m}}}
$$

Substituting the equivalent flux error into (14) and (16), the estimation errors of the speed and position can be reexpressed as:

$$
\left\{\begin{array}{l}
\Delta \omega_{\mathrm{m}}=-\frac{\psi_{\text {equ }}}{\psi_{\mathrm{f}}} \hat{\omega}_{\mathrm{m}} \\
\Delta \theta_{\mathrm{e}}=-\frac{K_{\alpha \beta}^{\prime} P_{\mathrm{n}} \hat{\omega}_{\mathrm{m}}}{K_{\mathrm{z}}} \frac{\psi_{\text {equ }}}{\psi_{\mathrm{f}}}
\end{array}\right.
$$

Although higher observer gain $K_{z}$ is beneficial in reducing the position estimation error, its effect is limited due to the restrictions imposed by the sensorless system stability conditions and the Signal-to-Noise-Ratio of the system, especially in the low speed region. As indicated in (18), the estimation errors of the speed and position are both in proportion to the equivalent flux error, and can be suppressed by compensating for $\psi_{\text {equ }}$ in the extended nonlinear observer. Fig. 6 shows the phasor diagram of PMSM considering the parameter inaccuracies.

As depicted in Fig. 6, the estimated back-EMF $\hat{\boldsymbol{E}}_{\alpha \beta}$ deviates from the actual back-EMF $\boldsymbol{E}_{\alpha \beta}$ both in magnitude and phase due to the inaccurate motor parameters. The magnitude difference will result in speed estimation error, whereas the phase difference will lead to $d$-axis current error $\Delta i$ and the position estimation error subsequently. The position estimation error dynamics can be extracted from (13) and rewritten as:

$$
\Delta \dot{\theta}_{\mathrm{e}}=P_{\mathrm{n}} \Delta \omega_{\mathrm{m}}-\frac{K_{\mathrm{z}}}{P_{\mathrm{n}} \hat{\omega}_{\mathrm{m}} \hat{\psi}_{\mathrm{f}}}\left(L_{\mathrm{s}} \Delta i\right)
$$

where, $\Delta i=\Delta i_{\alpha} \cos \hat{\theta}_{\mathrm{e}}+\Delta i_{\beta} \sin \hat{\theta}_{\mathrm{e}}$.

By substituting (18) into (19), the relationship between $\psi_{\text {equ }}$ and $\Delta i$ under steady-state condition can be derived.

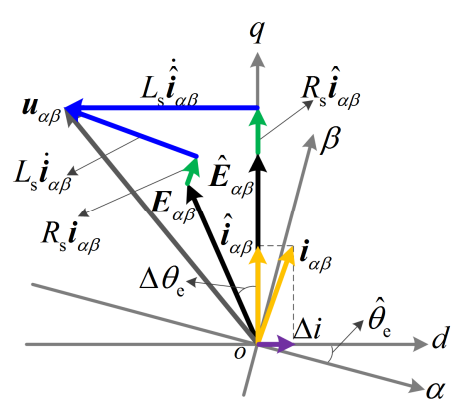

Fig. 6. Phasor diagram considering parameter inaccuracies 


$$
\psi_{\text {equ }}=-\frac{K_{\mathrm{z}} \psi_{\mathrm{f}}}{P_{\mathrm{n}} \omega_{\mathrm{m}} P_{\mathrm{n}} \hat{\omega}_{\mathrm{m}} \hat{\psi}_{\mathrm{f}}}\left(L_{\mathrm{s}} \Delta i\right)
$$

It is clear that, by considering the rotor speed to be constant in a very short time, the equivalent flux error is proportional to $\Delta i$, and can be compensated by forcing $\Delta i$ to be zero. Thus, the adaption law for the equivalent flux error can be designed as:

$$
\hat{\psi}_{\text {equ }}=\int-\frac{K_{\lambda}}{P_{\mathrm{n}}^{2} \hat{\omega}_{\mathrm{m}}^{2}}\left(L_{\mathrm{s}} \Delta i\right) d t
$$

where, $K_{\lambda} \in \mathbb{R}^{+}$is the gain for the estimation of the equivalent flux error.

To suppress the estimation errors of the speed and position caused by inaccurate motor parameters, the estimated equivalent flux error is supplemented into the extended nonlinear observer, as shown in the following:

$$
\left(\begin{array}{c}
L_{\mathrm{s}} \dot{\hat{i}}_{\alpha} \\
\dot{\hat{i}}_{\beta} \\
\dot{\hat{\omega}}_{\mathrm{m}} \\
\dot{\hat{\theta}}_{\mathrm{e}}
\end{array}\right)=\left(\begin{array}{c}
-\hat{R}_{\mathrm{s}} \hat{i}_{\alpha}+P_{\mathrm{n}} \hat{\omega}_{\mathrm{m}}\left(\hat{\psi}_{\mathrm{f}}+\hat{\psi}_{\text {equ }}\right) \sin \hat{\theta}_{\mathrm{e}}+u_{\alpha} \\
-\hat{R}_{\mathrm{s}} \hat{i}_{\beta}-P_{\mathrm{n}} \hat{\omega}_{\mathrm{m}}\left(\hat{\psi}_{\mathrm{f}}+\hat{\psi}_{\text {equ }}\right) \cos \hat{\theta}_{\mathrm{e}}+u_{\beta} \\
\left(T_{\mathrm{e}}^{\prime}-B \hat{\omega}_{\mathrm{m}}-\hat{T}_{\mathrm{L}}\right) / J \\
P_{\mathrm{n}} \hat{\omega}_{\mathrm{m}}
\end{array}\right)+\boldsymbol{K}\left(\begin{array}{c}
L_{\mathrm{s}} \Delta \hat{i}_{\alpha} \\
L_{\mathrm{s}} \Delta \hat{i}_{\beta}
\end{array}\right)
$$

\section{Experimental Studies}

The performance of the sensorless control system for PMSM based on the extended nonlinear observer with parameter uncertainty compensation is investigated on the testing platform based on fixed-point DSP TMS320F28234, as shown in Fig. 7.

The sampling frequency and the PWM frequency in the experimental tests are both set to $10 \mathrm{kHz}$. The DC bus voltage is measured, and the reference voltage $\boldsymbol{u}_{\alpha \beta}^{*}$ is fed to the extended nonlinear observer instead of the actual output voltage, along with the dead time and digital PWM delay compensated. A 2500-line incremental encoder is installed to measure the actual rotor position of PMSM, but only for reference purpose. The load torque imposed on the PMSM is generated by a permanent magnet synchronous

Table 1. Specifications of the prototype PMSM in simulation and experimental tests

\begin{tabular}{cc}
\hline Parameter & Value \\
\hline Rated Power & $1.0(\mathrm{~kW})$ \\
Rated Current & $5.0(\mathrm{~A})$ \\
Rated DC Voltage & $311(\mathrm{~V})$ \\
PM flux-linkage & $0.125(\mathrm{~Wb})$ \\
Stator Inductance & $2.8(\mathrm{mH})$ \\
Stator Resistance & $1.0(\Omega)$ \\
Pole Pairs & 4 \\
Rated Speed & $2000(\mathrm{rpm})$ \\
\hline
\end{tabular}

generator (PMSG) with a power-resistor as its load. The specifications of the prototype PMSM used in the simulation and experimental tests are given in Table 1.

Fig. 8 shows the experimental results of the sensorless control system with and without the load torque estimation. The reference speed is fixed to $500 \mathrm{rpm}$, with $3.2 \mathrm{~N} \cdot \mathrm{m}$ (65\% rated load) imposed on the shaft, and accurate motor

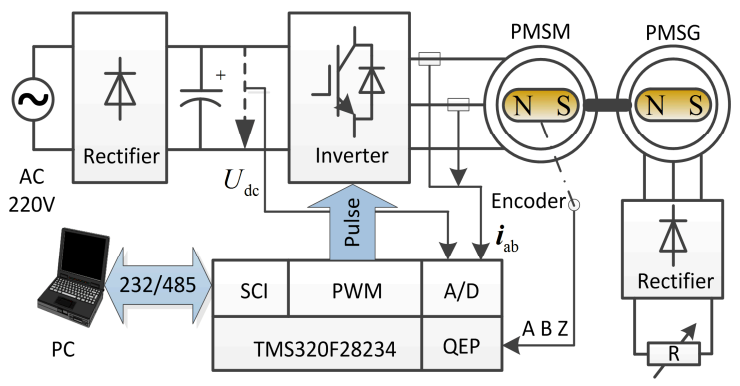

(a)

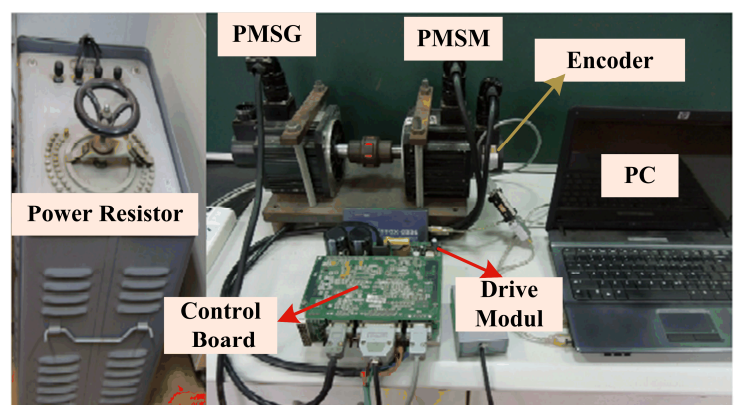

(b)

Fig. 7. Testing platform setup: (a) block diagram of the testing platform; (b) photograph of the testing platform
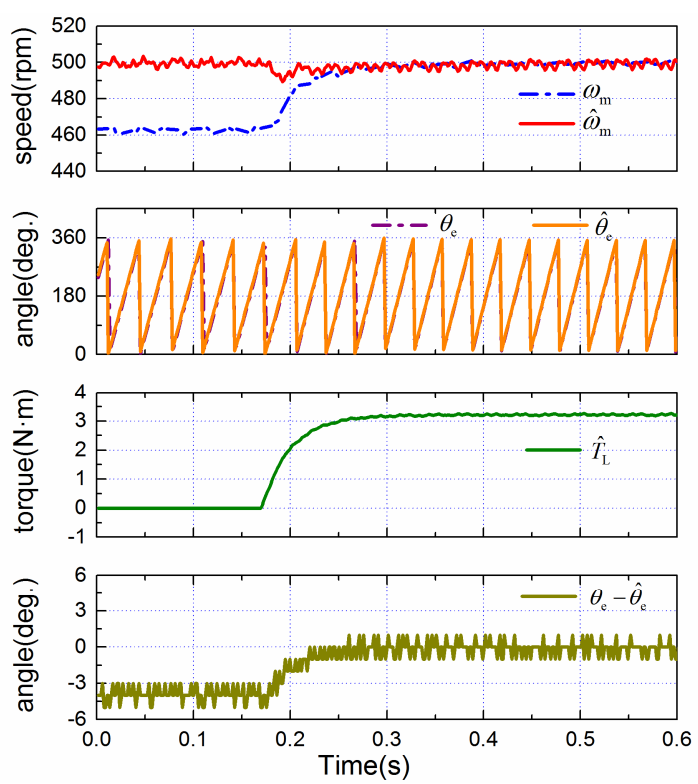

Fig. 8. Experimental results of the sensorless control system with and without load torque estimation 
parameters are adopted in the extended nonlinear observer. Large speed estimation error can be observed when the load torque estimation is disabled, corresponding to the left side of the dashed line. After the estimation for load torque is activated, the estimated load converges to its actual value within $0.1 \mathrm{~s}$, and the steady-state estimation errors of the speed and position are nearly zero, corresponding to the right side of the dashed line in Fig. 8.

Fig. 9 shows the experimental results with different stator resistance values adopted in the extended nonlinear observer. The Reference speed is fixed to $200 \mathrm{rpm}$ and torque-current $i_{q}$ is $2.1 \mathrm{~A}$ ( $30 \%$ of the rated current). To verify the effect of the stator resistance error on the estimated speed and position, the stator resistance adopted in the observer is deliberately set to $0.5 R_{\mathrm{s}}, R_{\mathrm{s}}, 1.5 R_{\mathrm{s}}$ respectively, while the PM flux-linkage is set to its actual

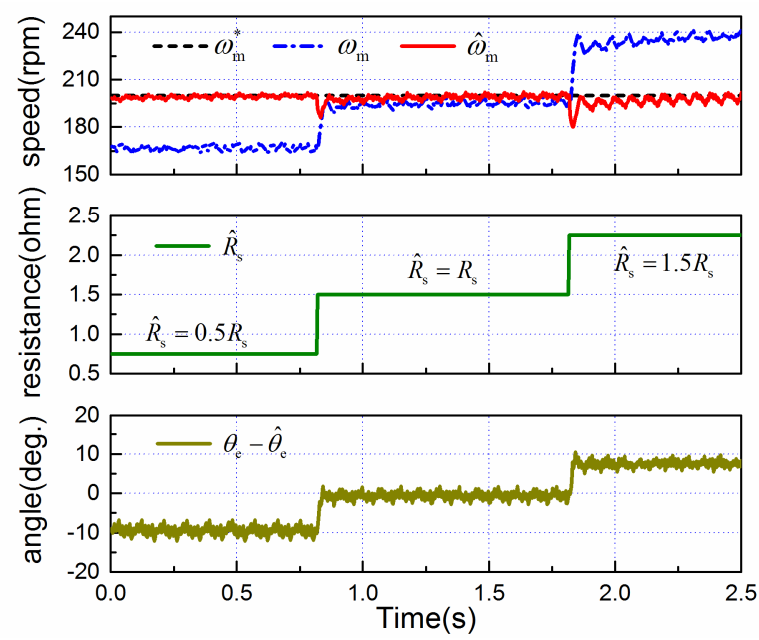

Fig. 9. Experimental results of the sensorless control system with different stator resistance values adopted in the extended nonlinear observer
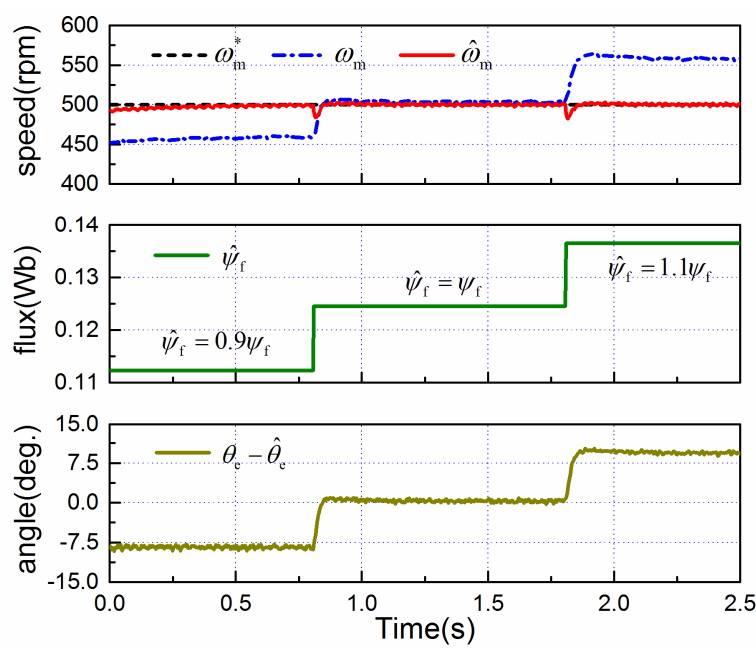

Fig. 10. Experimental results of the sensorless control system with different PM flux-linkage values adopted in the extended nonlinear observer value. From Fig. 9, it can be found that for $\hat{R}_{\mathrm{s}}=0.5 R_{\mathrm{s}}$, the speed estimation error is about $-35 \mathrm{rpm}$, and the position estimation error is about $-10^{\circ}$; for $\hat{R}_{\mathrm{s}}=R_{\mathrm{s}}$, the estimation errors of the speed and position are nearly zero; for $\hat{R}_{\mathrm{s}}=1.5 R_{\mathrm{s}}$, the speed estimation error is about $40 \mathrm{rpm}$, and the position estimation error is about $8^{\circ}$. The experimental results demonstrate that the stator resistance inaccuracy will cause significant estimation errors of the speed and position in the low speed region, which is in accordance with theoretical analysis.

Fig. 10 shows the experimental results with different PM flux-linkage values adopted in the extended nonlinear observer when the reference speed is set to $500 \mathrm{rpm}$ under no-load condition. To verify the effect of the PM flux error on the estimated speed and position, the PM flux-linkage adopted in the observer is set to $0.9 \psi_{\mathrm{f}}, \psi_{\mathrm{f}}, 1.1 \psi_{\mathrm{f}}$ respectively, while the stator resistance is set to its actual value. From Fig. 10, it can be found that for $\hat{\psi}_{\mathrm{f}}=0.9 \psi_{\mathrm{f}}$, the speed estimation error is about $-40 \mathrm{rpm}$, and the position estimation error is about $-8^{\circ}$; for $\hat{\psi}_{\mathrm{f}}=\psi_{\mathrm{f}}$, the estimation errors of the speed and position are nearly zero; for $\hat{\psi}_{\mathrm{f}}=1.1 \psi_{\mathrm{f}}$, the speed estimation error is about $60 \mathrm{rpm}$, and the position estimation error is about $10^{\circ}$. The experimental results demonstrate that the PM flux-linkage inaccuracy will also cause significant estimation errors of the speed and position, which is in accordance with theoretical analysis.

Fig. 11 shows the experimental results of the sensorless control system with and without compensation for the equivalent flux error when the stator resistance adopted in the extended nonlinear observer is deliberately set to $0.5 R_{\mathrm{s}}$. The PM flux-linkage is set to the actual value; the reference speed is set to $200 \mathrm{rpm}$, and the torque-current is $2.1 \mathrm{~A}(30 \%$ of the rated current). It is clear that the estimated speed deviates from the actual speed due to the

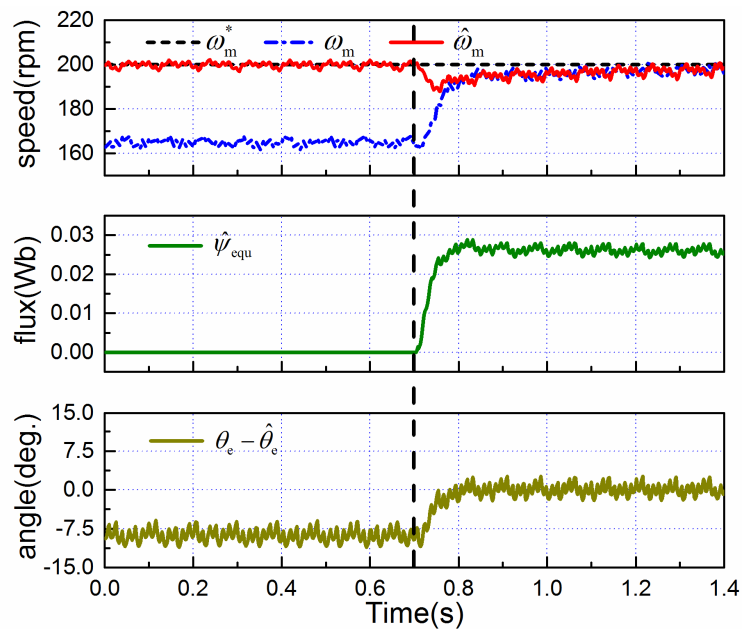

Fig. 11. Experimental results of the sensorless control system with and without compensation for the equivalent flux error when $\hat{R}_{\mathrm{s}}=0.5 R_{\mathrm{s}}$ is adopted in the extended nonlinear observer 
effect of the stator resistance inaccuracy, corresponding to the left side of the dashed line in Fig. 11. And the speed estimation error is about $-35 \mathrm{rpm}$, while the position estimation error is about $-10^{\circ}$. After compensation for the equivalent flux error is activated, corresponding to the right side of the dashed line in Fig. 11, the estimated speed and position gradually converge to their actual values. Estimation errors caused by the inaccurate stator resistance are effectively suppressed, and the steady-state estimation errors are nearly zero. Similar results can be obtained when the stator resistance adopted in the observer is set to $1.5 R_{\mathrm{s}}$.

Fig. 12 shows the experimental results of the sensorless control system with and without compensation for the equivalent flux error when the PM flux-linkage adopted in the extended nonlinear observer is deliberately set to $0.9 \psi_{\mathrm{f}}$. The stator resistance is set to the actual value in this test, and the reference speed is set to $1000 \mathrm{rpm}$ under no-load condition. It is clear that the estimated speed deviates from the actual speed due to the effect of the PM flux-linkage inaccuracy, corresponding to the left side of the dashed line in Fig. 12, with the speed and position estimation errors to be $-80 \mathrm{rpm}$ and $-13^{\circ}$ respectively. After compensation for the equivalent flux error is activated, corresponding to the right side of the dashed line in Fig. 12, the estimated speed and position gradually converge to their actual values. Estimation errors caused by the inaccurate PM flux-linkage are effectively suppressed, and the steady-state estimation errors are nearly zero. Similar results can be obtained when the PM flux-linkage adopted in the observer is set to $1.1 \psi_{\mathrm{f}}$.

Fig. 13 shows the speed tracking performance of the sensorless control system with and without compensation for the equivalent flux error. The stator resistance and PM flux-linkage are set to $0.5 R_{\mathrm{s}}$ and 0.9 respectively to simulate the practical worst conditions; the reference speed is set to accelerate from $200 \mathrm{rpm}$ to $1000 \mathrm{rpm}$ and reversely

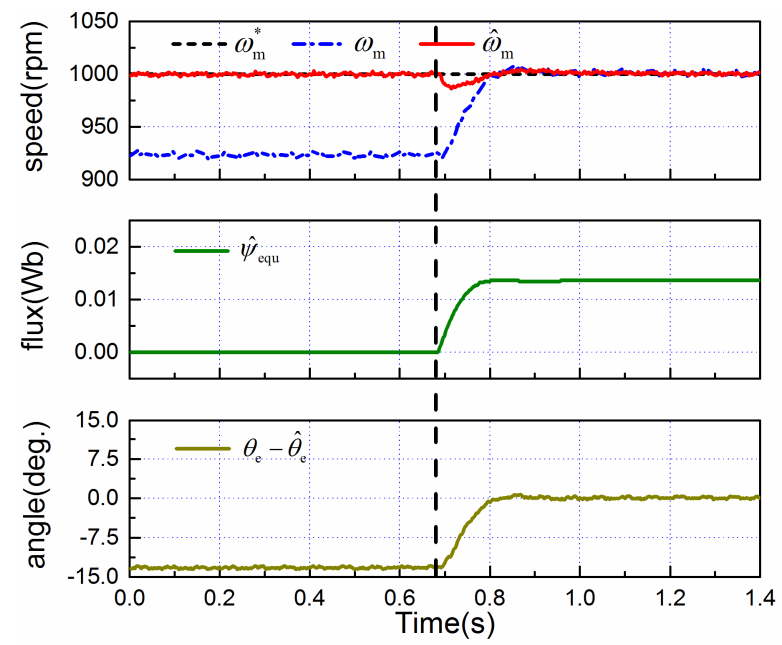

Fig. 12. Experimental results of the sensorless control system with and without compensation for the equivalent flux error when $\hat{\psi}_{\mathrm{f}}=0.9 \psi_{\mathrm{f}}$ is adopted in the extended nonlinear observer within $0.5 \mathrm{~s}$ time. At the meantime, the load torque imposed on the shaft is proportional to the actual speed approximately, and the maximum torque-current is $5.6 \mathrm{~A}$ ( $80 \%$ of the rated current). There is no equivalent flux error compensation in Fig. 13(a), and it can be seen that the estimation errors of the speed and position are proportional to the rotor speed, with their maximum values being -75 rpm and $-18^{\circ}$ respectively. After compensation for the equivalent flux error is activated, as shown in Fig. 13(b),
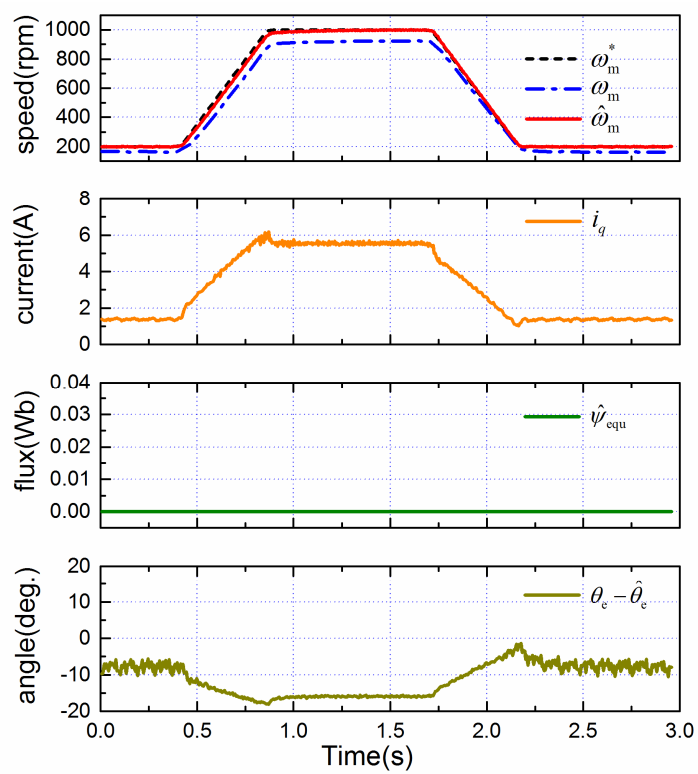

(a)
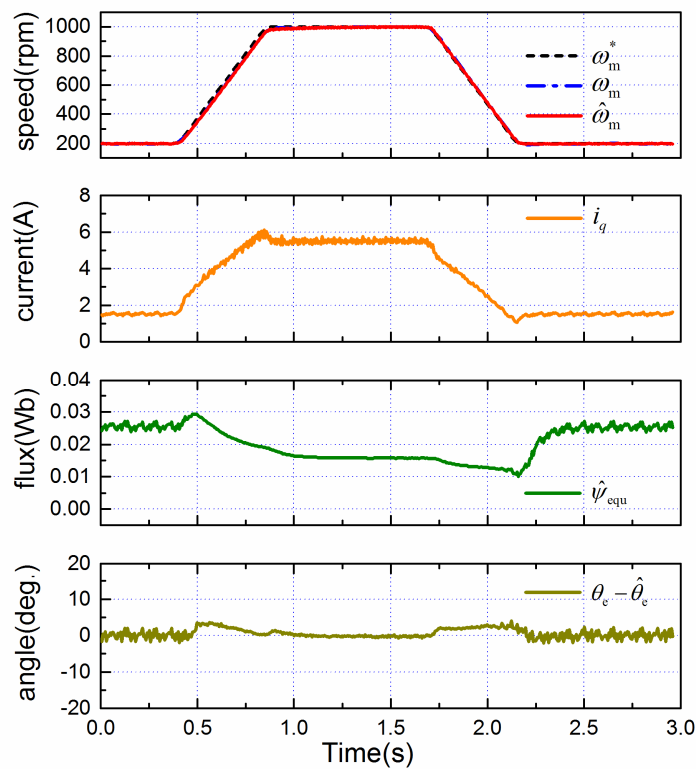

(b)

Fig. 13. Speed tracking performance of the sensorless control system when inaccurate stator resistance and PM flux-linkage are adopted in the extended nonlinear observer: (a) without compensation for the equivalent flux error; (b) with compensation for the equivalent flux error 

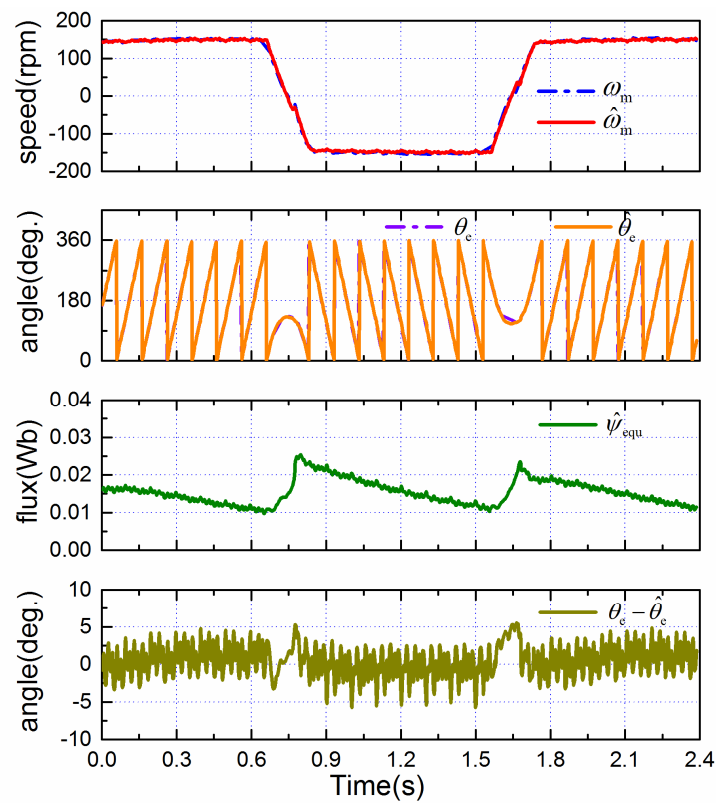

Fig. 14. Experimental results of speed reversal performance of the sensorless control system with compensation for the equivalent flux error

the effects of the inaccurate stator resistance and PM fluxlinkage are suppressed effectively, with the maximum estimation errors of the speed and position limited within $10 \mathrm{rpm}$ and $5^{\circ}$, and nearly zero steady-state estimation errors are obtained. Additionally, the actual speed tracks the reference speed well in both transient and steady-state periods.

Fig. 14 shows the speed reversal performance of the sensorless control system with compensation for the equivalent flux error under light-load condition. The stator resistance and PM flux-linkage are set to $0.5 R_{\mathrm{s}}$ and $0.9 \psi_{\mathrm{f}}$ respectively to simulate the worst conditions; the reference speed is set to decelerate from $150 \mathrm{rpm}$ to $-150 \mathrm{rpm}$ and reversely within $0.2 \mathrm{~s}$ time. As shown in Fig. 14, the estimated speed and position track their actual values well in both steady-state and transient periods, which demonstrate that the effects of the inaccurate stator resistance and PM flux-linkage are suppressed effectively. Although the signal-to-noise ratio is very poor in such low speed region, the results show stable operation during bidirection tests. The average steady-state position estimation error is nearly zero, whereas the transient estimation position estimation error is about $5^{\circ}$.

\section{Conclusion}

In this paper, an extended nonlinear observer with equivalent flux error compensation is proposed to improve the estimation accuracy of the rotor speed and position. Explicit estimation errors of the speed and position due to the parameter inaccuracies were derived and analyzed in detail. Although, the position estimation error can be reduced by properly adjusting the observer gains, its effect is limited due to the restrictions imposed by the sensorless system stability conditions and the SNR (Signal-to-NoiseRatio) of the system. As the estimation errors are essentially caused by the back-EMF estimation error, an equivalent flux error is defined to represent the effects of the parameter inaccuracies. And Instead of precisely identifying each motor parameter, a compensation strategy for the equivalent flux error is designed to eliminate the estimation errors of the position and speed. Experimental tests have demonstrated that accurate estimation for rotor speed and position can be achieved with the proposed method, insensitive to motor parameter uncertainties.

\section{Appendix A}

By assuming that the parameters adopted in the extended nonlinear observer are accurate, the error dynamic equation is derived by subtracting the extended nonlinear observer (4) from the dynamic models of PMSM (3), and subsequently transformed into the estimated SRFF, as shown in (A.1).

$$
\dot{x}=f(x)
$$

where, $\boldsymbol{x}=\left(\Delta i_{d} \Delta i_{q} \Delta \omega_{\mathrm{m}} \Delta \theta_{\mathrm{e}} \Delta T_{\mathrm{L}}\right)^{\mathrm{T}} ; \Delta i_{d}$ and $\Delta i_{q}$ are the stator current estimation errors in the estimated SRFF; and:

$$
\boldsymbol{f}(\boldsymbol{x})=\left(\begin{array}{c}
-K_{\alpha \beta}^{\prime} L_{\mathrm{s}} \Delta i_{d}+P_{\mathrm{n}} \omega_{\mathrm{m}} \psi_{\mathrm{f}} \sin \Delta \theta_{\mathrm{e}} \\
-K_{\alpha \beta}^{\prime} L_{\mathrm{s}} \Delta i_{q}-P_{\mathrm{n}} \psi_{\mathrm{f}}\left[\omega_{\mathrm{m}} \cos \Delta \theta_{\mathrm{e}}-\left(\omega_{\mathrm{m}}-\Delta \omega_{\mathrm{m}}\right)\right] \\
\left(-\Delta T_{\mathrm{L}}-B \Delta \omega_{\mathrm{m}}\right) / J+K_{\mathrm{z}} L_{\mathrm{s}} \Delta i_{q} / P_{\mathrm{n}} \psi_{\mathrm{f}} \\
P_{\mathrm{n}} \Delta \omega_{\mathrm{m}}-K_{\mathrm{z}} L_{\mathrm{s}} \Delta i_{d} / P_{\mathrm{n}} \psi_{\mathrm{f}}\left(\omega_{\mathrm{m}}-\Delta \omega_{\mathrm{m}}\right) \\
-K_{\mathrm{d}} J L_{\mathrm{s}} \Delta i_{q} / P_{\mathrm{n}} \psi_{\mathrm{f}}
\end{array}\right) .
$$

Evidently only one equilibrium point exits, that is $\boldsymbol{P}=0$. The local stability of the adaptive observer around $\boldsymbol{P}$ is studied using Indirect Lyapunov's Method. $\boldsymbol{J}=\partial \boldsymbol{f} / \partial \boldsymbol{x}$ is defined as the Jacobian matrix of the error dynamic equation, which can be obtained as follows:

$$
\begin{aligned}
& \boldsymbol{J}(\boldsymbol{x})= \\
& \left(\begin{array}{ccccc}
-K_{\alpha \beta}^{\prime} & 0 & 0 & P_{\mathrm{n}} \omega_{\mathrm{m}} \psi_{\mathrm{f}} \cos \Delta \theta_{\mathrm{e}} & 0 \\
0 & -K_{\alpha \beta}^{\prime} & -P_{\mathrm{n}} \psi_{\mathrm{f}} & P_{\mathrm{n}} \omega_{\mathrm{m}} \psi_{\mathrm{f}} \sin \Delta \theta_{\mathrm{e}} & 0 \\
0 & K_{\mathrm{z}} / P_{\mathrm{n}} \psi_{\mathrm{f}} & -B / J & 0 & -1 / J \\
-K_{\mathrm{z}} / P_{\mathrm{n}} \psi_{\mathrm{f}} \hat{\omega}_{\mathrm{m}} & 0 & P_{\mathrm{n}} & 0 & 0 \\
0 & -K_{\mathrm{d}} J / P_{\mathrm{n}} \psi_{\mathrm{f}} & 0 & 0 & 0
\end{array}\right)
\end{aligned}
$$

The linearized form of the error dynamic equation around equilibrium point $\boldsymbol{P}$ takes the following form: 


$$
\dot{\gamma}=\left.\boldsymbol{J}\right|_{x=p} \gamma
$$

where

$$
\begin{aligned}
& \left.\boldsymbol{J}(\boldsymbol{x})\right|_{x=p}= \\
& \left(\begin{array}{ccccc}
-K_{\alpha \beta}^{\prime} & 0 & 0 & P_{\mathrm{n}} \omega_{\mathrm{m}} \psi_{\mathrm{f}} & 0 \\
0 & -K_{\alpha \beta}^{\prime} & -P_{\mathrm{n}} \psi_{\mathrm{f}} & 0 & 0 \\
0 & K_{\mathrm{z}} / P_{\mathrm{n}} \psi_{\mathrm{f}} & -B / J & 0 & -1 / J \\
-K_{\mathrm{z}} / P_{\mathrm{n}} \psi_{\mathrm{f}} \omega_{\mathrm{m}} & 0 & P_{\mathrm{n}} & 0 & 0 \\
0 & -K_{\mathrm{d}} J / P_{\mathrm{n}} \psi_{\mathrm{f}} & 0 & 0 & 0
\end{array}\right)
\end{aligned}
$$

The asymptotical stability of the extended nonlinear observer can be determined by investigating its linearized approximation [23]. And the characteristic equation of the linearized form error dynamic equation can be derived as:

$$
\begin{aligned}
& \operatorname{det}\left(s \boldsymbol{I}-\left.\boldsymbol{J}\right|_{\boldsymbol{x}=\boldsymbol{p}}\right) \\
& \approx\left(s^{2}+K_{\alpha \beta}^{\prime} s+K_{\mathrm{z}}\right)\left(s^{3}+K_{\alpha \beta}^{\prime} s^{2}+K_{\mathrm{z}} s+K_{\mathrm{d}}\right)=0
\end{aligned}
$$

According to Routh's stability criterion, all the eigenvalues of (A.4) will be located on the left-half complex plane as long as $K_{\mathrm{d}}<K_{\mathrm{z}} K_{\alpha \beta}^{\prime}$ and $K_{\alpha \beta}>0$, $K_{\mathrm{z}}>0$, and $K_{\mathrm{d}}>0$, which indicates an asymptotically stable system.

\section{Acknowledgements}

This work was supported by the National Basic Research Program (973 Program) (2013CB035604) and the Natural Science Foundation of Zhejiang Province (LY14E070004).

\section{References}

[1] K. Ahn, A.E. Bayrak, and P.Y. Papalambros, "Electric Vehicle Design Optimization: Integration of a HighFidelity Interior-Permanent-Magnet Motor Model," IEEE Trans. Veh. Technol., vol. 64, no. 9, pp. 38703877, Sep. 2015.

[2] Y. Chen, P. Pillay, and A. Khan, "PM Wind Generator Topologies," IEEE Trans. Ind. Appl., vol. 41, no. 6, pp. 425-436, Nov./Dec. 2005.

[3] C.L Xia, W.T. Deng, and T.N. Shi, "Torque Ripple Minimization of PMSM Using Parameter Optimization Based Iterative Learning Control," Journal of Electrical Engineering \& Technology, vol. 11, no. 2, pp. 425-436, Mar. 2016.

[4] P. P. Acarnley and J. F. Watson, "Review of PositionSensorless Operation of Brushless Permanent-magnet Machines," IEEE Trans. Ind. Electron., vol. 53, no. 2, pp. 352-362, Apr. 2006.

[5] S.J. Kim, Y.K. Lee, J.S. Lee, K.W. Lee, T. Kwon, and H. Mok, "Sensorless Control Method in IPMSM Position Sensor Fault for HEV," Journal of Electrical Engineering \& Technology, vol. 8, no. 5, pp. 10561061, Sep. 2013.

[6] J. Holtz, "Acquisition of Position Error and Magnet Polarity for Sensorless Control of PM Synchronous Machines," IEEE Trans. Ind. Appl., vol. 44, no. 4, pp. 1172-1180, Jul./Aug. 2008.

[7] M. Seilmeier and B. Piepenbreier, "Sensorless Control of PMSM for the Whole Speed Range using Two-degree-of-freedom Current Control and HF Test Current Injection for Low-speed range," IEEE Trans. Power Electron., vol. 30, no. 8, pp. 4394-4403, Aug. 2015.

[8] D. Kim, Y. Kwon, S. Sul, and J. Kim, "Suppression of Injection Voltage Disturbance for High-Frequency Square-wave Injection Sensorless Drive with Regulation of Induced High-Frequency Current Ripple," IEEE Trans. Ind. Appl., vol. 52, no. 1, pp. 302-312, Jan./Feb. 2016.

[9] P. Kshirsagar, R. Burgos, J. Jang, A. Lidozzi, F. Wang, D. Boroyevich, and S. Sul, "Implementation and Sensorless Vector-control Design and Tuning Strategy for SMPM Machines in Fan-type Applications," IEEE Trans. Ind. Appl., vol. 30, no. 8, pp. 2402-2413, Nov./Dec. 2012.

[10] B. Nahid-Mobarakeh, F. Meibody-Tabar, and F. Sargos, "Back EMF Estimation-based Sensorless Control of PMSM: Robustness with Respect to Measurement Errors and Inverter Irregularities," IEEE Trans. Ind. Appl., vol. 43, no. 2, pp. 485-494, Mar./Apr. 2015.

[11] T. Bernardes, V. Montagner, H. Grundling, and H. Pinheiro, "Discrete-time Sliding Mode Observer for Sensorless Vector Control of Permanent Magnet Synchronous Machine," IEEE Trans. Ind. Electron., vol. 61, no. 4, pp. 1679-1691, Apr. 2014.

[12] J. Dominguez, A. Navarrete, M. Meza, A. Loukianov, and J. Canedo, "Digital Sliding-mode Sensorless Control for Surface-mounted PMSM," IEEE Trans. Ind. Informat., vol. 10, no. 1, pp. 137-151, Feb. 2014.

[13] Y. Fan, L. Zhang, M. Cheng, and K. Chau, "Sensorless SVPWM-FADTC of a New Flux-modulated Permanent-magnet Wheel Motor Based on a Widespeed Sliding Mode Observer," IEEE Trans. Ind. Electron., vol. 62, no. 5, pp. 3143-3151, May 2015.

[14] G. Zhang, G. Wang, D. Xu, and N. Zhao, "Adalinenetwork-based PLL for Position Sensorless Interior Permanent Magnet Synchronous Motor Drives," IEEE Trans. Power Electron., vol. 31, no. 2, pp. 1450-1460, Feb. 2016.

[15] L. Idkhajine, E. Monmasson, and A. Maalouf, "Fully FPGA-based Sensorless Control for Synchronous AC Drive using an Extended Kalman Filter," IEEE Trans. 
Ind. Electron., vol. 59, no. 10, pp. 3908-3918, Oct. 2012.

[16] N. Quang, N. Hieu, and Q.P. Ha, "FPGA-Based Sensorless PMSM Speed Control Using ReducedOrder Extended Kalman Filters," IEEE Trans. Ind. Electron., vol. 61, no. 2, pp. 6574-6582, Dec. 2014.

[17] M. Rashed, P.F.A. MacConnell, A.F. Stronach, and P. Acarnley, "Sensorless Indirect-rotor-field-orientation Speed Control of a Permanent-magnet Synchronous Motor with Stator-resistance Estimation," IEEE Trans. Ind. Electron., vol. 54, no. 3, pp. 1664-1675, Jun. 2007.

[18] Y. Shi, K. Sun, L. Huang, and Y. Li, "Online Identification of Permanent Magnet Flux Based on Extended Kalman Filter for IPMSM Drive with Position Sensorless Control," IEEE Trans. Ind. Electron., vol. 59, no. 11, pp. 4169-4178, Nov. 2012.

[19] G. Bisheimer, M.O. Sonnaillon, C.H. De Angelo, J.A. Solsona, and G.O. Garcia, "Full Speed Range Permanent Magnet Synchronous Motor Control without Mechanical Sensors," IET Electr. Power Appl., vol. 4, no. 1, pp. 35-44, 2010.

[20] G. Zhu, A. Kaddouri, L.A. Dessaint, and O. Akhrif, "A Nonlinear State Observer for the Sensorless Control of a Permanent-magnet AC Machine," IEEE Trans. Ind. Electron., vol. 48, no. 6, pp. 1098-1108, Dec. 2001.

[21] B. Bhangu and C. Bingham, "GA-tuning of Nonlinear Observers for Sensorless Control of Automotive Power Steering IPMSMs," Proc. IEEE Vehicle Power and Propulsion, pp. 772-779, 2005.

[22] J. A. Solsona, M. I. Valla, and C. Muravchik, "Nonlinear Control of a Permanent Magnet Synchronous Motor with Disturbance Torque Estimation," IEEE Trans. Energy Convers., vol. 15, no. 2, pp. 163-168, Jun. 2000.

[23] Driels, MR. Nonlinear Systems: Analysis, Stability, and Control. Springer, New York, p. 182-223, 1999.

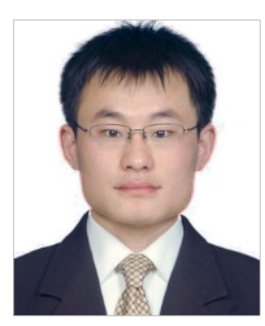

Yongle Mao was born in China, in 1986. He received his B.S. and M.S. degrees in Electrical Engineering from the Harbin Institute of Technology (HIT), Harbin, China, in 2009 and 2011, respectively. $\mathrm{He}$ is presently working towards his Ph.D. degree in the College of Electrical Engineering, Zhejiang University, Hangzhou, China. His current research interests include sensorless control and parameter identification in AC machines.

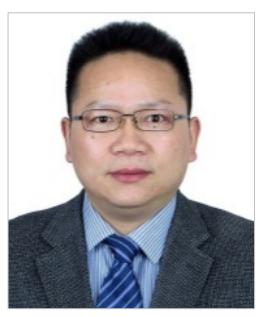

Jiaqiang Yang was born in China, in 1970. He received his Ph.D. degree in Electrical Engineering from Zhejiang University, Hangzhou, China, in 2004. He has been an Associate Professor in the College of Electrical Engineering, Zhejiang University, Hangzhou, China, since 2006. He was a research fellow at the National University of Singapore, Singapore, from March 2011 to April 2012. His current research interests include power electronics, electric machine drives, and control strategies.

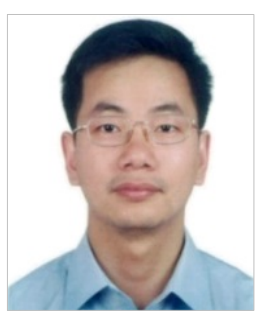

Yangsheng Chen was born in China, in 1969. He received his B.S. and M.S. degrees in Electrical Engineering from Zhejiang University, Hangzhou, China, in 1991 and 1994, respectively; and his Ph.D. degree in Department of Electric and Electrical Engineering from the University of Sheffield, Sheffield, England, UK, in 1999. He was a Principal Engineer in CT and TRW, where he lead many significant projects, including high power density motors for industrial robots, aero electrical drive systems for flight control, the development of servo motors for the ABS/EPS/ABC systems in automobiles, and research on ECUs and sensors. He has been a Professor in the College of Electrical Engineering, Zhejiang University, Hangzhou, China, since 2005. His current research interests include permanent magnet synchronous control, the application of power electronics, motor designs for automobiles and related control systems, motor electromagnetism theory, and research on motor vibrations and noise. 